\title{
Imagination inflation: A statistical artifact of regression toward the mean
}

\author{
KATHY PEZDEK and REBECCA M. EDDY \\ Claremont Graduate University, Claremont, California
}

\begin{abstract}
In the imagination inflation procedure of Garry, Manning, Loftus, and Sherman (1996), subjects rated a list of events in terms of how likely each was to have occurred in their childhood. Two weeks later, some of the events were imagined; control events were not. The subjects then rated the likelihood of occurrence for each event a second time. Garry et al. (1996) reported that the act of imagining the target events led to increased ratings of likelihood. This finding has been interpreted as indicating that false events can be suggestivelyplanted in memory by simply having people imagine them. The present study tests and confirms the hypothesis that the results that have been attributed to imagination inflation are simply a statisticalartifact of regression toward the mean. The experiment of Garry et al. (1996) was reproduced (with some procedural changes), using younger and older adults. The results of Garry et al. (1996) were replicated; likelihood ratings for events initially rated low in likelihood did increase from Time 1 to Time 2. However, ratings for events initially rated high in likelihood decreased under the same conditions, and these results were consistent with the imagined target events, the target events not imagined, and the nontarget events.
\end{abstract}

Regression toward the mean is an artifact that as easily fools statistical experts as lay people. The universal phenomenon of regression toward the mean is just as universally misunderstood. Regression toward the mean is a very subtle phenomenon and easy to miss. (Campbell \& Kenny, 1999, p. xiii)

This study addresses the conditions under which false autobiographical events are likely to be planted in memory and the potential role of regression toward the mean in interpreting some of the research findings on this topic. In a number of studies, it has been reported that it is possible to plant false events in memory. For example, Loftus and Pickrell (1995) had 24 volunteers suggest to an offspring or younger sibling that he or she had been lost in a mall while shopping when he or she was about 5 years old. Six of the 24 subjects reported either full or partial memory for the false event. Similarly, Hyman, Husband, and Billings (1995) asked college students about their memory for numerous true events and two false events. The percentage of subjects who recalled the false events as real was $20 \%$ in Experiment 1 and $25 \%$ in Experiment 2. And Ceci, Huffman, Smith and Loftus (1996) read preschool children a list of true and false

These findings were presented at the 1999 meeting of the Society for Applied Research in Memory and Cognition in Boulder, Colorado, and at the 2000 meeting of the American Psychology-Law Society in New Orleans. We are extremely grateful to John Vokey at the University of Lethbridge for reviewing this manuscript and providing us with the suggestion to perform the statistical analysis of the mean residual differences. We thank two other reviewers, J. Don Read and Robert Belli, for their helpful comments and Richard Eddy for his patience and invaluable contributions. Correspondence concerning this article should be addressed to K. Pezdek, Department of Psychology, Claremont Graduate University, Claremont, CA 91711-3955(e-mail: kathy.pezdek@ cgu.edu). events and asked them to "think real hard about each" event and "try to remember if it really happened." In the initial session, $44 \%$ of the children $3-4$ years of age and $25 \%$ of the children 5-6 years of age remembered at least one of the false events.

On the other hand, there are clear constraints on the conditions under which false events can be planted in memory (see Pezdek \& Hinz, in press, for a review of these constraints). Pezdek and Roe (1997), for example, reported that although entirely new false events can be planted in children's memory, it is relatively more difficult to suggestively plant a memory for a touch to the body that did not occur than to suggestively change a memory for a touch that did occur. Also, Pezdek, Finger, and Hodge (1997) reported that plausible false events are more likely to be planted in memory than implausible false events. In the second experiment in this study, 20 confederate experimenters read descriptions of one true event and two false events to a younger sibling or close relative. One false event described the relative's being lost in a mall while shopping (the plausible event); the other false event described the relative's receiving a rectal enema (the implausible event). More subjects recalled the false event that involved being lost $(n=3)$ than the false event that involved the enema $(n=0)$. Similar results were reported with 5- to 7-year-old and 9- to 12-yearold children by Pezdek and Hodge (1999).

Recently, Garry, Manning, Loftus, and Sherman (1996) investigated the possibility that childhood events could be suggestively planted in memory by having subjects simply think about the to-be-planted event once. This procedure, called imagination inflation, assesses the extent to which people's confidence that an event occurred in childhood was increased after imagining the event. In 
the study by Garry et al. (1996), young adults completed a Life Events Inventory (LEI), in which they rated the likelihood that each of 40 events had happened to them before the age of 10 on a scale from 1 (definitely did not happen) to 8 (definitely did happen); we call these likelihood ratings. The list included 8 target events. Two weeks after completing the LEI, the subjects were asked to imagine 4 target events; the other 4 target events served as not-imagined control events. After imagining the events, the subjects completed the LEI a second time. The results, in terms of the percentage of events that stayed the same, increased, or decreased for events ini- tially rated 1-4 (indicating that the target event probably did not occur), are presented in the top panel of Figure 1. The major finding was that the majority of scores did not change from Time 1 to Time 2. However, when scores did change, positive change scores were more likely to occur than were negative ones. The authors stated that "imagining a self-reported counterfactual event increased confidence that the event did happen" (p. 213). In summarizing the results of this experiment and several others using the imagination inflation paradigm, Garry and Polaschek (2000) concluded that "a growing body of literature shows that imagining contrary-to-truth experiences

Garny et al. (1996)

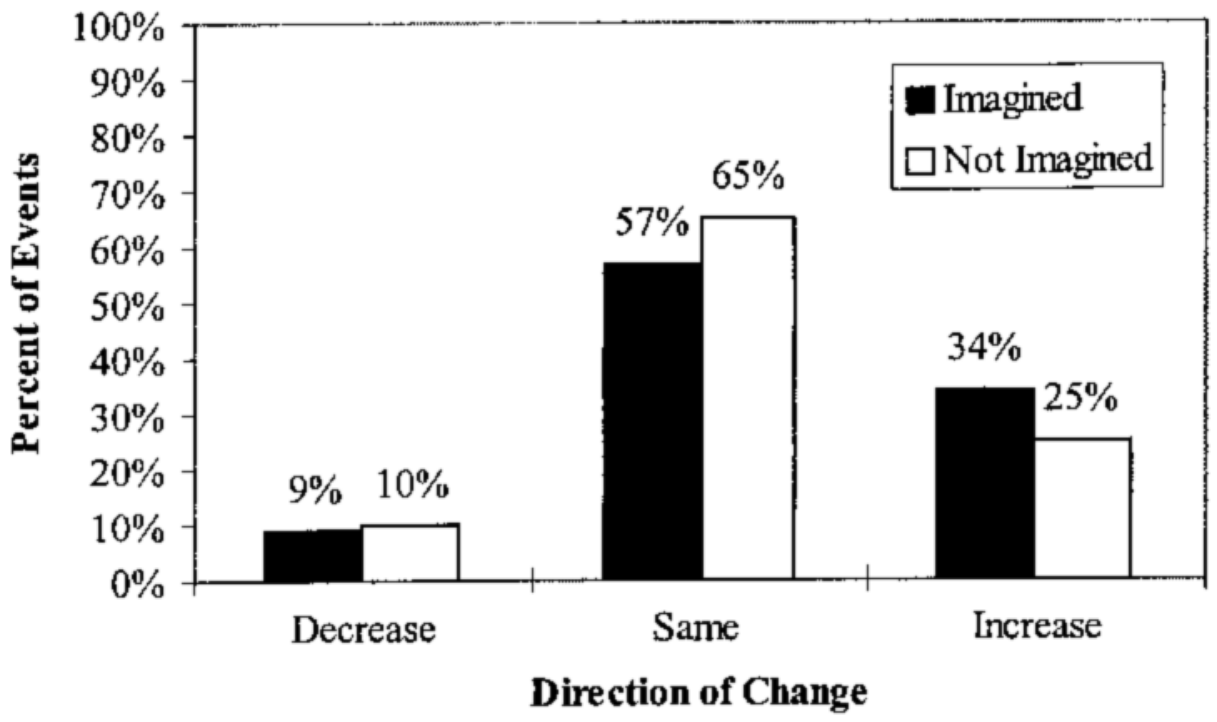

Pezdek \& Eddy

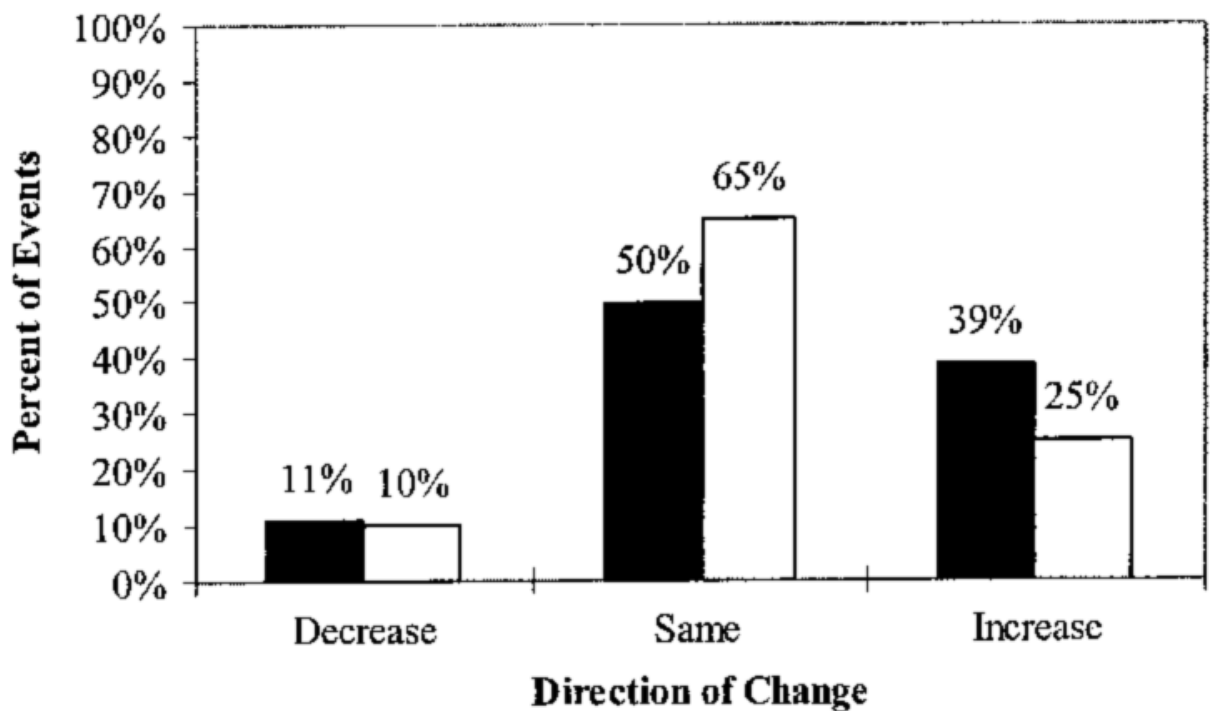

Figure 1. Percentage of target events that decreased, stayed the same, or increased for subjects who initially responded 1-4 in Garry, Manning, Loftus, and Sherman (1996) and in the present paper. 
can change memory" (p. 6). Furthermore, "when people think about or imagine a false event, entire false memories can be implanted. Imagination inflation can occur even when there is no overt social pressure, and when hypothetical events are imagined only briefly" (p. 6).

This study was motivated by concerns about an alternative interpretation of the findings of Garry et al. (1996). Two results in their study suggested that perhaps their findings could be explained as simply a case of regression toward the mean. First, for events initially rated 1-4, likelihood ratings increased for both imagined and not-imagined events. Although there were more imagined events (34\%) for which ratings increased from Time 1 to Time 2 than not-imagined events $(25 \%$; significance tests of this difference could not be conducted, since individual subjects contributed different numbers of events to each condition), nonetheless this finding suggested that regression toward the mean might explain the upward shift in scores that occurred in both conditions. Second, we recently obtained from the authors their findings regarding the events initially rated 5-8 (C. G. Manning, personal communication, May 19, 1999). These data, not reported in the published study, are presented in the top panel of Figure 2. As can be seen, when scores did change from Time 1 to Time 2 for these events, $44 \%$ decreased ( 32 of 73 ), only $16 \%$ increased (12 of 73), and this pattern of results was consistent for both imagined and not-imagined events. These findings are exactly what would be predicted by regression toward the mean: When gathering data on the same measurement scale twice, scores below the mean tend to increase, and scores above the mean tend to decrease.

We also sought additional information not provided by Garry et al. (1996). Although they reported the percentage of events that changed from Time 1 to Time 2, they did not report the mean likelihood ratings at Time 1 and Time 2 for events in the imagined versus the not-imagined conditions, nor did they report the magnitude of the change in mean likelihood ratings from Time 1 to Time 2 in each condition. The mean magnitude of the change in likelihood ratings from Time 1 to Time 2, rather than simply the percentage of events changed, contains more descriptive information from which to assess whether false events were really planted in memory. If imagining an event increased likelihood ratings by 4 or 5 points on a scale from 1 to 8 , this would be far more impressive than if the mean increase was only 1 or 2 points.

The procedure used in this experiment was similar to the imagination inflation procedure utilized by Garry et al. (1996) and subsequently revised by Garry, Manning, and Loftus (1997). We were primarily interested in the statistical analysis of the ratings of all target events, not just those initially rated as not likely to have occurred. In addition, to provide a specific test of whether the results of Garry et al. (1996) reflect suggested changes in the underlying memories, we included older adults (mean age $=76$ years), as well as younger adults (mean age $=$ 21 years), in this study. If the results of Garry et al. (1996) reflect the extent to which false autobiographical events are suggestively planted in memory, the change in likelihood ratings from Time 1 to Time 2 would be expected to be greater for older adults than for younger adults. This prediction follows from the finding of Cohen and Faulkner (1989) that older adults are more suggestible than younger adults.

If the imagination inflation procedure does assess the extent to which false events are planted in memory, several predictions would follow. First, mean likelihood ratings for all imagined target events, not just for those initially rated 1-4, would increase from Time 1 to Time 2. Second, the change in likelihood ratings from Time 1 to Time 2 would significantly interact with the imagination condition, so that ratings for imagined events would change more than ratings for events not imagined. Third, the time $\times$ imagination condition $\times$ age interaction would be significant, so that the change in likelihood ratings from Time 1 to Time 2 in the imagined condition would be greater for older than for younger adults. On the other hand, if the results simply reflect regression toward the mean, then (1) likelihood ratings for events initially rated 1-4 would be more likely to increase and likelihood ratings for events initially rated 5-8 would be more likely to decrease from Time 1 to Time 2, (2) the change in scores from Time 1 to Time 2 would not interact with imagination condition, and (3) none of the effects involving the imagination condition would interact with age.

\section{METHOD}

\section{Subjects and Design}

Seventy-five subjects completed all the phases of Experiment 1. The subjects included one group of 32 older adults (age, $M=75.66$ years, $S D=6.18$ ) and one group of 43 younger adults (age, $M=$ 20.93 years, $S D=3.58$ ). The younger adults were students in an introductory psychology class at a local community college and received course credit for participating in the experiment. The older adults were recruited from a local senior citizens community center, and each older adult received $\$ 10$ for his or her participation. Mean vocabulary test scores (maximum score $=25$ ) administered during the experiment significantly differed between the two groups $[t(73)=$ $6.44, p<.01]$, with vocabulary scores higher for older adults $(M=$ $18.09, S D=5.26)$ than for younger adults $(M=11.44, S D=3.69)$. This finding is typical in studies comparing older and younger adults and suggests that the two age samples were from comparable populations. This was a 2 (older vs. younger adults) $\times 2$ (imagined vs. not-imagined events) $\times 2$ (Time 1 vs. Time 2 ) mixed factorial design, with age as the only between-subjects variable. The dependent variable was the likelihood rating on a scale from 1 (definitely did not happen) to 8 (definitely did happen) for the target events on the LEI.

\section{Materials}

During the first experimental session, all the subjects completed a 19-item LEI similar to the instrument used by Garry et al. (1996). Whereas Garry et al. (1996) used a 40-item LEI, we used the 20item LEI utilized by Garry et al. (1997), with one item deleted because it did not translate across cultures. It was also necessary to modify some events in the LEI to indicate more culturally appropriate descriptions of events (e.g., "Shook hands with the Prime Minister" was changed to "Shook hands with the Governor"). The 
Garry et al. (1996)

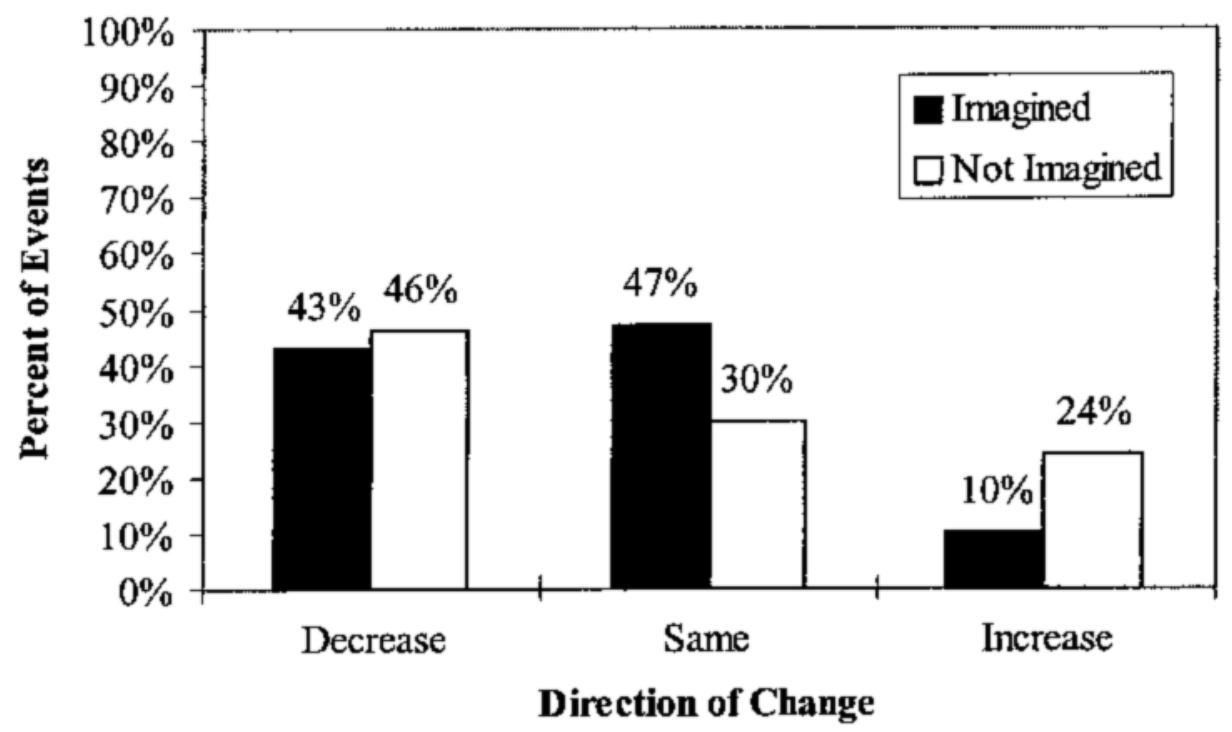

Pezdek \& Eddy

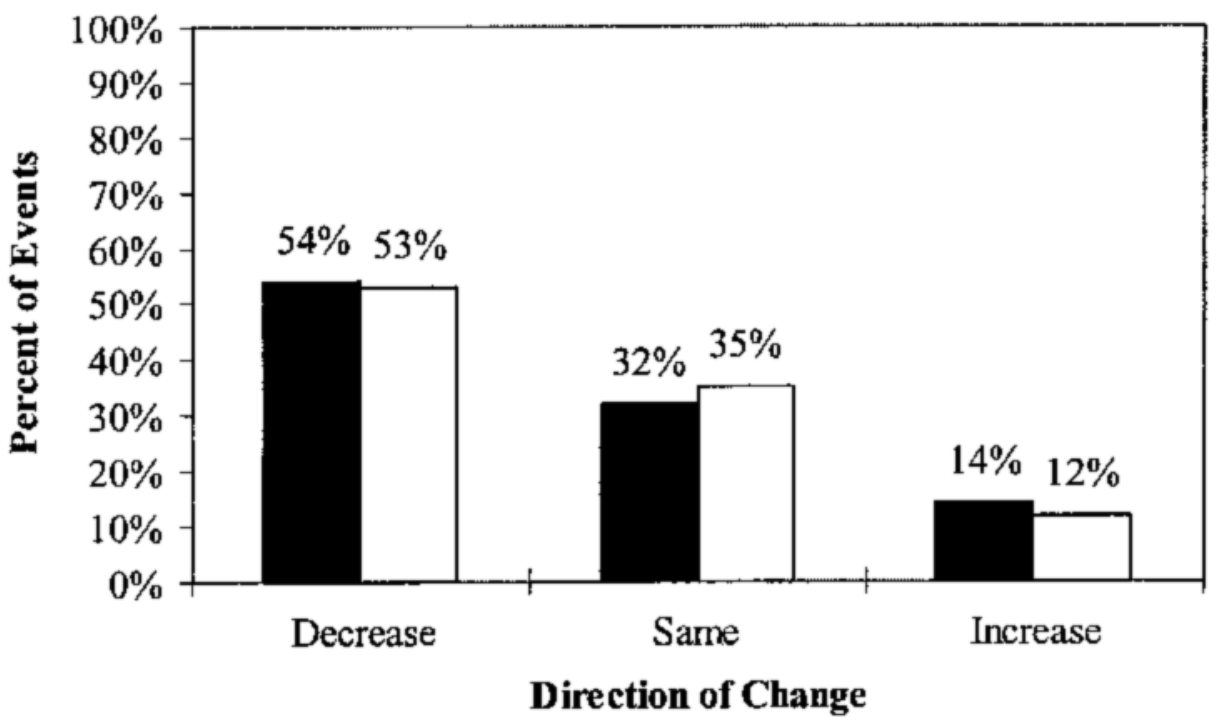

Figure 2. Percentage of target events that decreased, stayed the same, or increased for subjects who initially responded 5-8 in Garry, Manning, Loftus, and Sherman (1996) and in the present paper.

19 events used in this study are listed in the Appendix. Four of these were target events, and 15 were nontarget events. In the Garry et al. (1996) study, 4 target events were imagined, and 4 target events were not imagined per subject. In the interest of time, in this study, the subjects imagined 2 of the 4 target events, and the other 2 target events were not imagined. Three of the 4 target events used in this study were target events from the Garry et al. (1996) study. The assignment of target events to the imagined and not-imagined conditions was counterbalanced across subjects, as was the order of presentation, so that each target item was assigned to the imagined and not-imagined conditions equally often.

\section{Procedure}

The procedures used were similar to those in Garry et al. (1996). All the subjects participated in small groups in two phases of the experiment. During the first phase, each subject completed the 19-item LEI with no time limit. The subjects rated how likely it was that each event happened to them before the age of 10 by circling the corresponding number on a scale from 1 (definitely did not happen) to 8 (definitely did happen). This dependent measure will be called the likelihood ratings. A standard vocabulary test was administered after the first LEI was completed. After completing the first phase, the subjects were dismissed and instructed to return 2 weeks later. 
In the second phase of the study, the subjects were instructed to imagine two of the four target events. During the imagination sequence, the experimenter instructed the subjects to imagine that each of two target childhood events had happened to them before the age of 10 and to respond in writing to four questions about the imagined scenario. The questions were included to aid in the imagining of the physical details of each event. As each target event was presented, the subjects were instructed as follows:

I am interested in how elaborately people can imagine events that they may have experienced in their life. I am going to ask you to imagine each of two events. As I read you a description of each event, I am going to ask you to picture the event in your memory in as much detail as possible. I will speak slowly and give you as much time as you need to develop a clear image of the event in your mind. It will help you to form a complete mental picture if you include familiar places, people, and objects in your image. Feel free to close your eyes while you form your image or to look at a neutral focal point in this room. On the sheet in front of you, please write your answer to each of the questions that I ask you.

Each subject was allowed 3-5 min to imagine each event and to write down the description.

After completing the imagination sequence, the subjects completed the LEI a second time. The LEI in the second session was identical to the LEI in the first session, with the same instructions given both times. The subjects were allowed unlimited time to complete the inventory and were debriefed after all materials had been collected. The timing of the imagination sequences and the administration of the second LEI followed the procedures of Garry et al. (1996).

\section{RESULTS}

\section{Analyses Comparable With Those of Garry et al. (1996): Events With Initial LEI Ratings of 1-4}

The data were first analyzed as in Garry et al. (1996) to assess whether their results were replicated here. The general pattern of results for target events initially rated 1-4 is presented in Figure 1 for both this experiment and that by Garry et al. (1996). Since Garry et al. (1996) did not report the results for target events initially rated 5-8, the results reported in the top panel of Figure 1 are the principal findings on which they based their conclusions. In the present experiment, $75 \%$ of the target events were initially rated 1-4 (high likelihood that the event had not occurred in childhood), and 25\% were initially rated 5-8 (high likelihood that the event had occurred in childhood). In this experiment, for target events initially rated $1-4$, a majority of the ratings for both the imagined $(50 \%)$ and the not-imagined $(65 \%)$ events stayed the same from Time 1 to Time 2. This is comparable to the result of Garry et al. (1996) that for target events initially rated $1-4$, ratings of $57 \%$ for the imagined target events and $65 \%$ for the not-imagined target events stayed the same from Time 1 to Time 2. Also similar to the findings of Garry et al. (1996), when ratings changed from Time 1 to Time 2, the direction of change was more likely an increase than a decrease, as is shown in Figure 1. In this study, whereas the ratings for $39 \%$ of the imagined target events and $25 \%$ of the not-imagined target events increased from Time 1 to Time 2, the ratings of only $11 \%$ of the imagined target events and $10 \%$ of the not-imagined target events decreased from Time 1 to Time 2. Similarly, Garry et al. (1996) reported that whereas the ratings for $34 \%$ of the imagined target events and $25 \%$ of the not- imagined target events increased from Time 1 to Time 2, the ratings for only $9 \%$ of the imagined target events and $10 \%$ of the not-imagined target events decreased from Time 1 to Time 2. It is thus clear that the major findings of Garry et al. (1996) were replicated in this experiment.

\section{Analyses of Events With Initial LEI Ratings of 5-8}

A second set of analyses was conducted to compare the change in likelihood ratings from Time 1 to Time 2 for target events initially rated 5-8 (high likelihood that the event had occurred in childhood). This analysis was conducted to investigate the possibility that the changes in the likelihood ratings simply reflected regression toward the mean - that although events initially rated low on the likelihood scale tended to increase when the subjects rated them a second time, events initially rated high on the likelihood scale tended to decrease when the subjects rated them a second time. The general pattern of results for events initially rated 5-8 is presented in Figure 2 for both this experiment and that by Garry et al. (1996). As can be seen in Figure 2, the findings are remarkably similar in these two experiments. In this experiment, for target events initially rated 5-8, a majority of the ratings for both the imagined (54\%) and the not-imagined (53\%) target events decreased from Time 1 to Time 2. This is comparable to the results of Garry et al. (1996), that for the events initially rated 5-8, ratings of $43 \%$ of the imagined target events and $46 \%$ of the not-imagined target events decreased from Time 1 to Time 2 . In both experiments, few of the target events initially rated 5-8 increased from Time 1 to Time 2. In this experiment, only $14 \%$ of the imagined target events and $12 \%$ of the notimagined target events increased from Time 1 to Time 2. In the experiment by Garry et al. (1996), ratings for only $10 \%$ of the imagined target events and $24 \%$ of the notimagined target events increased from Time 1 to Time 2. Across both experiments, it is especially noteworthy that the pattern of change in ratings was remarkably similar for imagined and not-imagined target events. This suggests that the results were not caused solely by the act of imagining the target events.

\section{Analyses of Nontarget Events}

If regression toward the mean is operative in the imagination inflation paradigm, it should be evidenced with the nontarget events, as well as with the target events. To assess this prediction, the change in likelihood ratings from Time 1 to Time 2 for the 15 nontarget events was assessed for the events initially rated 1-4 and for those initially rated 5-8. As with the target events, the majority of the nontarget events $(61 \%)$ were initially rated $1-4$. The pattern of results observed with the target events was replicated with the nontarget events. First, the modal pattern for nontarget events was for the likelihood ratings to stay the same from Time 1 to Time 2 (62\% for events initially rated $1-4$ and $49 \%$ for events initially rated 5-8). When likelihood ratings did change from Time 1 to Time 2 for the nontarget events initially rated 
$1-4$, the change was more likely to be an increase (30\%) than a decrease $(8 \%)$. When likelihood ratings did change from Time 1 to Time 2 for the nontarget events initially rated 5-8, the change was more likely to be a decrease $(41 \%)$ than an increase $(10 \%)$. The similar pattern of results with target and nontarget events supports the significant role of regression toward the mean in accounting for results of the imagination inflation paradigm. These results should also assuage concerns that the findings in this study are item-specific effects.

\section{Tests of Regression Toward the Mean With Events With Extreme Initial LEI Ratings}

If regression toward the mean is operative in the imagination inflation paradigm, it would also be predicted that events initially assigned ex treme likelihood ratings would show more regression toward the mean than would events initially assigned less extreme likelihood ratings. To assess this prediction, the change in likelihood ratings from Time 1 to Time 2 was examined for events initially rated $1-2,3-4,5-6$, and 7-8. These results were examined separately for imagined target events, not-imagined target events, and nontarget events. These data are presented in Table 1. Significance tests could not be conducted on these data, since the factors are neither independent nor nonindependent. However, a clear pattern can be observed in the descriptive data. For all three types of eventsimagined target events, not-imagined target events, and nontarget events - the change in scores from Time 1 to Time 2 was greater for the events initially rated $1-2$ than for events initially rated 3-4 and greater for events initially rated $7-8$ than for events initially rated $5-6$. These results support the significant role of regression toward the mean in accounting for the results of the imagination inflation paradigm.

\section{Analyses Using Target Events as the Unit of Analysis}

In support of their conclusions regarding the existence of imagination inflation, Garry et al. (1996) compared the imagined target events with the target events not imagined in terms of the percentage of subjects for whom likelihood ratings increased from Time 1 to Time 2 for events that were initially rated $1-4$. Treating events as the unit of analysis, they reported a significant paired $t$ test, with the percentage of subjects who positively changed from Time 1 to Time $28.2 \%$ greater for imagined events than for events not imagined. We performed this same analysis in this study and found similar results. With the four target events as the unit of analysis and only the target events that were initially rated $1-4$ being considered, the percentage of subjects for whom likelihood ratings increased from Time 1 to Time 2 was $14.2 \%$ greater for imagined events than for events not imagined $[t(3)=$ $2.65, p<.05]$. In contrast, when we performed a comparable analysis on the target events that were initially rated $5-8$, the percentage of subjects for whom likelihood ratings decreased from Time 1 to Time 2 did not significantly differ between imagined events and events not imagined $(t<1.0)$. Although these results suggest a role of imagination inflation over and above the effect of regression toward the mean, this conclusion is not consistent with findings obtained when the data are analyzed not simply in terms of how many people increased their likelihood ratings from Time 1 to Time 2, but rather in terms of the actual magnitude of the change in likelihood ratings that did occur.

\section{Assessing the Magnitude of the Change in LEI Ratings}

Next, the data were analyzed to assess the magnitude of the change in likelihood ratings from Time 1 to Time 2 for events initially rated $1-4$. Table 2 shows the mean ratings for each of the four target events at Time 1 and Time 2 and the change in ratings for each event. Weighted means were computed because the total number of subjects contributing to the mean for each item varied. The data for imagined target events are presented in the left panel of Table 2. For imagined target events initially rated 1-4, the mean amount of change from Time 1 to Time 2 was only 1.13 points on the $1-8$ scale. With the exception of one item ("Saw a shooting star"), for imagined events initially rated $1-4$, the mean rating at Time 2 remained on the 1-4 (did not happen) end of the scale. The data for target events not imagined are presented in the right panel of Table 2. Ratings for not-imagined events initially rated 1-4 also indicate a small mean change from Time 1 to Time 2, only 0.68 points. For each of the four target events, the mean likelihood rating at Time 2 also remained on the 1-4 (did not happen) end of the scale. Also, it is worth noting that for events initially rated $1-4,51 \%$ of the increases in likelihood ratings for imagined target events were increases of only 1 or 2 points; for target events not imagined, $34.5 \%$ of the increases in LEI scores were increases of only 1 or 2 points. For target events initially rated $1-4$, when large rating increases of

Table 1

Mean Changes in Likelihood Ratings (With Standard Deviations) for Imagined Target Events, Not-Imagined Target Events, and Nontarget Events as a Function of Whether the Event Was Initially Rated 1-2, 3-4, 5-6, or 7-8

\begin{tabular}{|c|c|c|c|c|c|c|c|c|c|c|c|c|c|c|c|c|c|c|}
\hline \multirow{3}{*}{$\begin{array}{l}\text { Events Initially } \\
\text { Rated }\end{array}$} & \multicolumn{6}{|c|}{ Imagined } & \multicolumn{6}{|c|}{ Not Imagined } & \multicolumn{6}{|c|}{ Nontarget } \\
\hline & \multicolumn{2}{|c|}{ Time 1} & \multicolumn{2}{|c|}{ Time 2} & \multirow[b]{2}{*}{ Change } & \multirow[b]{2}{*}{$N$} & \multicolumn{2}{|c|}{ Time 1} & \multicolumn{2}{|c|}{ Time 2} & \multirow[b]{2}{*}{ Change } & \multirow[b]{2}{*}{$N$} & \multicolumn{2}{|c|}{ Time 1} & \multicolumn{2}{|c|}{ Time 2} & \multirow[b]{2}{*}{ Change } & \multirow[b]{2}{*}{$N$} \\
\hline & $M$ & $S D$ & $M$ & $S D$ & & & $M$ & $S D$ & $M$ & $S D$ & & & $M$ & $S D$ & $M$ & $S D$ & & \\
\hline $1-2$ & 1.15 & 0.36 & 2.59 & 2.50 & 1.44 & 82 & 1.07 & 0.26 & 1.78 & 1.69 & 0.71 & 94 & 1.08 & 0.27 & 2.09 & 2.07 & 1.01 & 592 \\
\hline & 3.7 & 0.4 & 3.93 & 1.8 & & 27 & & 0.50 & & & & 22 & 71 & 0.4 & 3.86 & 2.11 & & \\
\hline & 5.32 & 0.48 & 4.14 & 1.9 & & 22 & & 0.52 & & & & 11 & 5.41 & 0.49 & 4.84 & 2.25 & & 10 \\
\hline $7-8$ & 7.89 & 0.32 & 6.21 & 2.86 & -1.68 & 19 & 7.83 & 0.39 & 5.87 & 2.75 & -1.96 & 23 & 7.87 & 0.34 & 6.38 & 2.39 & -1.49 & 33 \\
\hline
\end{tabular}


Table 2

Mean Changes in Likelihood Ratings (With Standard Deviations) for Target Events Initially Rated 1-4 as a Function of Imagination Condition and Time

\begin{tabular}{|c|c|c|c|c|c|c|c|c|c|c|c|c|}
\hline \multirow[b]{3}{*}{ Event } & \multicolumn{6}{|c|}{ Imagined } & \multicolumn{6}{|c|}{ Not Imagined } \\
\hline & \multicolumn{2}{|c|}{ Time 1} & \multicolumn{2}{|c|}{ Time 2} & \multirow[b]{2}{*}{ Change } & \multirow[b]{2}{*}{$N$} & \multicolumn{2}{|c|}{ Time 1} & \multicolumn{2}{|c|}{ Time 2} & \multirow[b]{2}{*}{ Change } & \multirow[b]{2}{*}{$N$} \\
\hline & $M$ & $S D$ & $M$ & $S D$ & & & $M$ & $S D$ & $M$ & $S D$ & & \\
\hline Saw a shooting star & 2.70 & 1.29 & 4.52 & 2.25 & 1.82 & 23 & 2.12 & 1.41 & 3.59 & 2.98 & 1.47 & 17 \\
\hline $\begin{array}{l}\text { Broke a window } \\
\text { with your hand }\end{array}$ & 1.09 & 0.28 & 1.71 & 1.43 & 0.62 & 35 & 1.13 & 0.35 & 1.27 & 0.87 & 0.14 & 30 \\
\hline $\begin{array}{l}\text { Found a } \$ 10 \text { bill } \\
\text { in a parking lot }\end{array}$ & 1.60 & 1.04 & 3.20 & 2.81 & 1.60 & 25 & 1.56 & 1.03 & 2.28 & 1.86 & 0.72 & 36 \\
\hline $\begin{array}{l}\text { Got stuck in a tree and } \\
\text { had to have someone } \\
\text { help you down }\end{array}$ & 2.08 & 1.32 & 2.85 & 2.43 & 0.77 & 26 & 1.64 & 1.14 & 2.36 & 2.21 & 0.72 & 33 \\
\hline
\end{tabular}

more than 3 points did occur from Time 1 to Time 2, they were more likely to occur for events that were not imagined $(65 \%)$ than for events that were imagined $(49 \%)$. This finding provides additional evidence that the results were not a product of the subjects' imagining the target events.

In the analysis above, the change in likelihood ratings for each of the four target events when they were initially rated 1-4 was examined. We next compared the mean changes in likelihood ratings from Time 1 to Time 2 for events initially rated $1-4$ and for events initially rated 5-8. These descriptive data, presented in Figure 3, are plotted separately for the imagined target events, the not-imagined target events, and the nontarget events. It is clear that, as would be predicted by regression toward the mean, the mean likelihood ratings for events initially rated 1-4 increased from Time 1 to Time 2, the mean likelihood ratings for events initially rated 5-8 decreased from Time 1 to Time 2, and the trend was similar for the imagined target events, the not-imagined target events, and the nontarget events.

An additional descriptive analysis was conducted to examine the magnitude of the change in likelihood ratings only for the events that increased or decreased from Time 1 to Time 2 . There were 300 target events all together (4 target events for each of 75 subjects), of which 154 were unchanged from Time 1 to Time 2. This analysis was conducted on the remaining 146 events. These data are presented in Table 3. As can be seen in the top panel of Table 3 , in the imagined condition, the events initially rated 1-4 that increased from Time 1 to Time 2 increased by approximately the same magnitude $(M=3.32)$ as the events initially rated 5-8 decreased by $(M=-3.04)$. Also, the events initially rated $1-4$ that decreased from Time 1 to Time 2 decreased by approximately the same magnitude $(M=-1.58)$ as the events initially rated 5-8 increased by $(M=1.50)$. Furthermore, as can be seen in the middle and bottom panels of Table 3, this same trend occurred with target events not imagined and with nontarget events. Significance tests cannot be conducted on these data, since these factors are neither independent nor nonindependent, the subjects differed in terms of whether they contributed to each cell in this 2 (event initially rated
1-4 or 5-8) $\times 2$ (ratings increased or decreased) matrix, as well as how frequently they contributed to each cell. Nonetheless, it is clear from the descriptive data that the magnitude of the regression toward the mean for events with initial low likelihood ratings was approximately the same as the magnitude of the regression toward the mean for events with initial high likelihood ratings and that this trend was similar for imagined target events, for target events not imagined, and for nontarget events. Also, shifts in likelihood ratings away from the mean were not only infrequent (see Figures 1 and 2), but also of a smaller mean magnitude than were shifts in ratings toward the mean. These data provide additional support for the conclusion that the results produced in the imagination inflation paradigm are evidence of regression toward the mean.

\section{Analysis of Variance}

Additional analyses were performed on the data to assess patterns of results beyond those addressed by Garry et al. (1996). A repeated factors analysis of variance (ANOVA) was conducted to compare the effects of time, imagination condition, and age group on likelihood ratings for target events. All results are considered significant at the $p<.05$ level. The main effect of time was significant $\left[F(1,73)=4.23, M S_{\mathrm{e}}=1.56\right]$, as was the main effect of imagination condition $\left[F(1,73)=3.95, M S_{\mathrm{e}}=\right.$ 2.83]. Ratings increased significantly from Time $1(M=$ $2.96)$ to Time $2(M=3.26)$. Ratings were significantly greater for imagined events $(M=3.30)$ than for events not imagined $(M=2.91)$. However, imagination condition did not significantly interact with time $[F(1,73)=$ $\left.0.78, M S_{\mathrm{e}}=1.36\right]$ or age group $\left[F(1,73)=0.83, M S_{\mathrm{e}}=\right.$ $2.83]$, nor was the time $\times$ age $\times$ imagination condition interaction significant $\left[F(1,73)=1.36, M S_{\mathrm{e}}=1.36\right]$.

\section{Testing Regression Toward the Mean Directly}

The most direct statistical test of regression toward the mean was conducted with this final analysis. ${ }^{1}$ This test was conducted on each of the four target events separately, with subjects as the unit of analysis. For each target event, this analysis included only those subjects for whom the Time 1 LEI score in the imagine condition was below the mean for that event at Time 1 in the imagine condition. 


\section{Target and Nontarget Events Initially Rated 1-4}

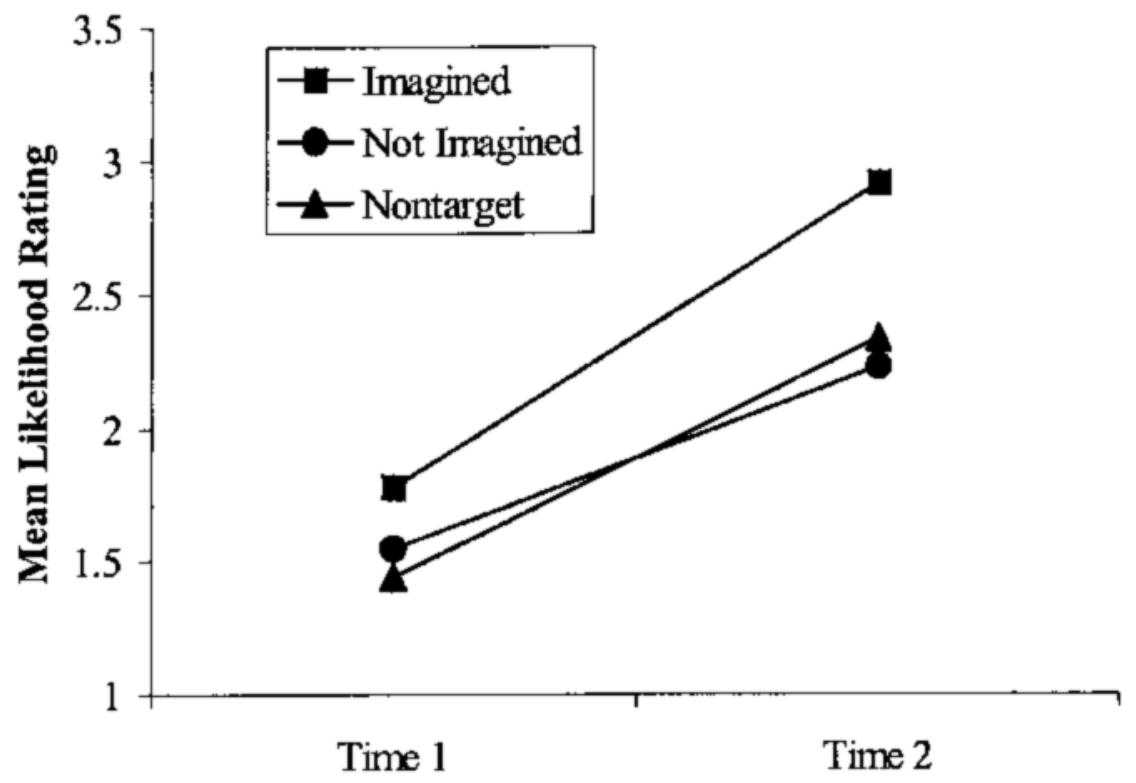

Target and Nontarget Events Initially Rated 5-8

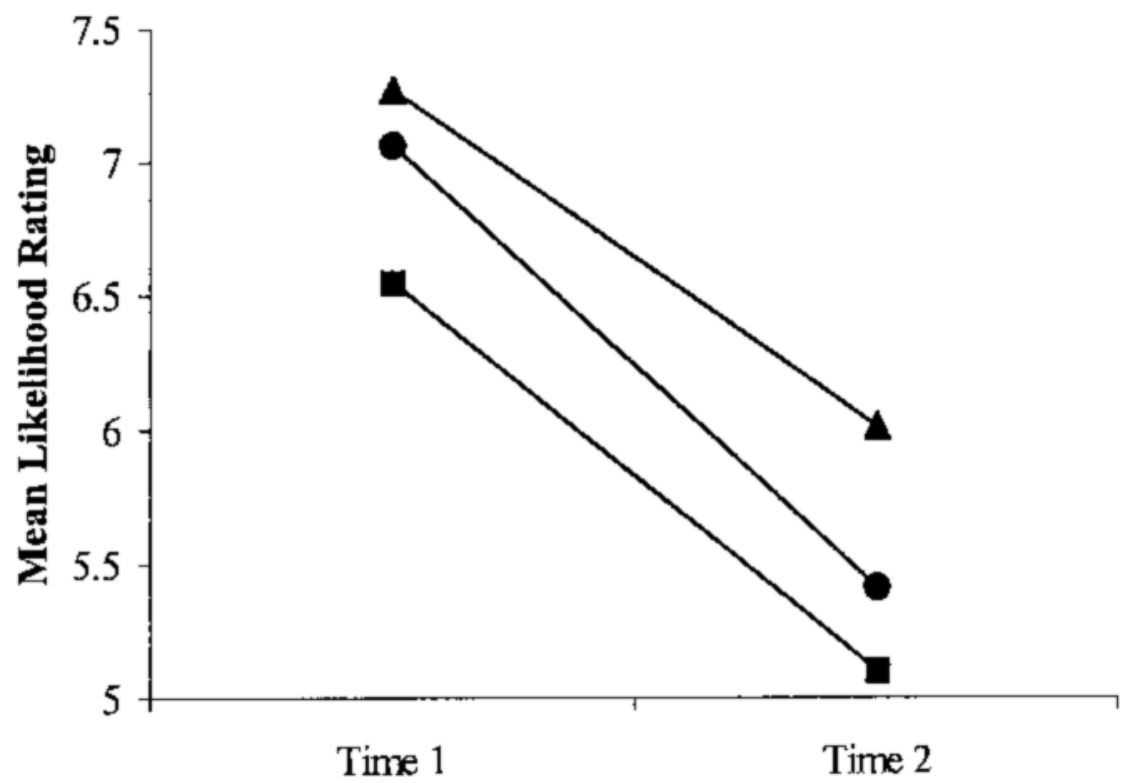

Figure 3. Mean changes in likelihood ratings from Time 1 to Time 2 for target events initially rated 1-4 versus 5-8.

This is the condition for which the strongest predictions of imagination inflation were made by Garry et al. (1996). In this analysis, if nothing but regression toward the mean is accounting for the results, then for events initially rated below the mean in the imagine condition, the mean residual difference - that is, the mean difference between the obtained Time 2 LEI score $(y)$ and the predicted Time 2 LEI score $\left(y^{\prime}\right)$ - should be randomly distributed with an expected value of zero, where $Z_{y^{\prime}}=\left(r_{x y}\right)\left(Z_{x}\right)$, and $r_{x y}$ is the correlation between the Time 1 LEI score and the Time 2 LEI score for all subjects in the control condition. In other words, if nothing but regression toward the 
Table 3

\begin{tabular}{|c|c|c|c|c|c|c|c|c|c|c|c|c|}
\hline \multirow{3}{*}{$\begin{array}{l}\text { Initially } \\
\text { Rated }\end{array}$} & \multicolumn{6}{|c|}{ Increased } & \multicolumn{6}{|c|}{ Decreased } \\
\hline & \multicolumn{2}{|c|}{ Time 1} & \multicolumn{2}{|c|}{ Time 2} & \multirow[b]{2}{*}{ Change } & \multirow[b]{2}{*}{$N$} & \multicolumn{2}{|c|}{ Time 1} & \multicolumn{2}{|c|}{ Time 2} & \multirow[b]{2}{*}{ Change } & \multirow[b]{2}{*}{$N$} \\
\hline & $M$ & $S D$ & $M$ & $S D$ & & & $M$ & $S D$ & $M$ & $S D$ & & \\
\hline \multicolumn{13}{|c|}{ Imagined } \\
\hline $1-4$ & 1.98 & 1.22 & 5.30 & 2.08 & 3.32 & 43 & 3.33 & 0.78 & 1.75 & 0.87 & -1.58 & 12 \\
\hline $5-8$ & 5.50 & 0.84 & 7.00 & 0.89 & 1.50 & 6 & 6.18 & 1.26 & 3.14 & 1.83 & -3.04 & 22 \\
\hline \multicolumn{13}{|c|}{ Not Imagined } \\
\hline $1-4$ & 1.79 & 1.21 & 5.14 & 2.13 & 3.35 & 29 & 3.00 & 0.85 & 1.50 & 0.67 & -1.50 & 12 \\
\hline $5-8$ & 5.75 & 0.96 & 7.00 & 1.15 & 1.25 & 4 & 6.89 & 1.18 & 3.50 & 2.04 & -3.39 & 18 \\
\hline \multicolumn{13}{|c|}{ Nontarget Items } \\
\hline $1-4$ & 1.56 & 1.02 & 4.94 & 2.21 & 3.38 & 207 & 3.33 & 0.83 & 1.71 & 0.80 & -1.62 & 52 \\
\hline $5-8$ & 5.81 & 0.74 & 7.50 & 0.67 & 1.69 & 42 & 7.16 & 1.17 & 3.74 & 2.13 & -3.42 & 182 \\
\hline
\end{tabular}

mean is occurring, as we contend, then in the imagine condition, the actual Time 2 LEI scores obtained should not differ significantly from the Time 2 LEI scores predicted from the regression equations derived for each event in the control condition. On the other hand, if imagination inflation is occurring then for each event, the mean residual difference should be significantly greater than zero, indicating that the Time 2 LEI score in the imagined condition predicted from $r_{x y}$ for all subjects in the control condition was less than the actual Time 2 LEI score obtained in the imagine condition.

Following this procedure, the residual was computed for each of the four target events separately. These values are presented in Table 4. A one-sample $t$ test yielded the residual for each of the four target events to be nonsignificantly different from zero. Thus, for imagined events that were initially rated as unlikely to have occurred in one's childhood, beyond the effect of regression toward the mean, there was no consistent variance in the change in LEI scores from Time 1 to Time 2 to be accounted for by any other factors. This analysis of the data provides the strongest statistical basis for concluding that regression toward the mean-not imagination inflation-accounts for the obtained results.

\section{DISCUSSION}

In this experiment, the imagination inflation procedure was used to assess whether imagining several target childhood events increased ratings of the likelihood that

Table 4

Mean Residual Difference ( $y-y^{\prime}$; With Standard Deviations) Calculated on Each Target Event Separately for Subjects Who Initially Rated the Event Below the Mean in the Imagine Condition

\begin{tabular}{lcccc}
\hline & \multicolumn{2}{c}{ Residual Difference } & & \\
\cline { 2 - 3 } \multicolumn{1}{c}{ Event } & $M$ & $S D$ & & $t$ Value \\
\hline Saw a shooting star & 0.80 & 2.35 & 16 & 1.36 \\
Broke a window & 0.32 & 1.68 & 33 & 1.10 \\
Found a \$10 bill & 0.30 & 2.92 & 21 & 0.46 \\
Got stuck in a tree & 0.42 & 2.01 & 22 & 0.98 \\
\hline
\end{tabular}

the events had occurred, as had been concluded by Garry et al. (1996). The major findings in the study by Garry et al. (1996) were replicated in this experiment, suggesting that when the data from both studies were analyzed similarly, the same results occurred; ratings for events initially rated 1-4 were more likely to increase than to decrease. Although these findings were interpreted by Garry et al. (1996) as evidence that imagining the specific target events results in increased confidence that the events are part of one's autobiography, an alternative interpretation exists. The alternative interpretation is that the change in ratings from Time 1 to Time 2 is a statistical artifact of regression toward the mean. Garry and Polaschek (2000) briefly considered this interpretation but concluded that it was "easily dismissed" (p. 9). Several additional analyses were included in this experiment specifically to assess the role of regression toward the mean in accounting for the results of Garry et al. (1996). The two interpretations can be differentiated on the basis of four specific predictions.

First, if the imagination inflation procedure assesses the extent to which events are planted in one's autobiographical memory, mean likelihood ratings for all imagined target events, not just for those initially rated $1-4$, would increase from Time 1 to Time 2 . As can be seen in Figure 1, as compared with Figure 2, and in the top as compared with the bottom panel of Figure 3, in this experiment, as well as in that of Garry et al. (1996), although the mean likelihood ratings for events initially rated 1-4 increased from Time 1 to Time 2, the mean likelihood ratings for events initially rated 5-8 decreased from Time 1 to Time 2. Furthermore, shifts in likelihood ratings toward the mean were not only more frequent, as can be seen in Table 3, but also of a larger mean magnitude than were shifts in likelihood ratings away from the mean, and this trend was similar for the imagined target events, for the target events not imagined, and for the nontarget events. These results support the interpretation that the change in likelihood ratings from Time 1 to Time 2 occurred as a result of regression toward the mean.

Second, if the imagination inflation procedure assesses the extent to which events are planted in one's autobio- 
graphical memory, the change in likelihood ratings from Time 1 to Time 2 will significantly interact with imagination condition, so that ratings for imagined events would change more than ratings for events not imagined. This prediction could not be tested in the study by Garry et al. (1996) because an ANOVA was not reported on those data. The ANOVA conducted on the data in this experiment resulted in a nonsignificant interaction of time with the imagination condition $(F<1)$. Furthermore, for target events initially rated $1-4$, when large rating increases of more than 3 points did occur from Time 1 to Time 2, they were more likely to occur for events that were not imagined (65\% of positive change scores for events not imagined) than for events that were imagined (49\% of positive change scores for imagined target events). Again, these results suggest that the change in likelihood ratings from Time 1 to Time 2 occurred as a result of regression toward the mean and does not reflect a change in memory as a result of imagining the target events.

Third, if the imagination inflation procedure assesses the extent to which events are suggestively planted in one's autobiographical memory, the change in likelihood ratings from Time 1 to Time 2 would be greater for older adults than for younger adults. This prediction follows from the finding of Cohen and Faulkner (1989) that older adults are more suggestible than younger adults. This experiment included older $(M$ age $=75.66$ years $)$ and younger $(M$ age $=20.93$ years $)$ adults to specifically test this prediction. None of the effects involving age significantly affected the likelihood ratings. This result supports the interpretation that the change in likelihood ratings from Time 1 to Time 2 does not reflect a suggestive change in memory as a result of imagining the target events.

Fourth, the strongest test of whether the results from the imagination inflation paradigm result from the planting of the imagined event in memory or from regression toward the mean is provided in the analysis of the mean residual differences, $y-y^{\prime}$, in the imagine condition. That is, if imagination inflation accounts for the results, then for events initially rated below the mean in the imagine condition, the mean difference between $y$, the actual obtained Time 2 LEI score, and $y^{\prime}$, the Time 2 LEI score predicted by the equation $Z_{y^{\prime}}=\left(r_{x y}\right)\left(Z_{x}\right)$ should be significantly greater than zero. As is presented in Table 4 , for each of the four target events, the mean residual difference was not statistically significant. It is clear that for the imagined events that were initially rated as unlikely to have occurred in one's childhood, beyond the effect of regression toward the mean, there is no consistent variance in the change in LEI scores from Time 1 to Time 2 that can be accounted for by any other factors. This analysis of the data provides the strongest statistical basis for concluding that regression toward the mean, and not imagination inflation, accounts for the obtained results.

Because the procedure used in this study did not exactly replicate that of Garry et al. (1996), it might be argued that this study simply presents a failure to replicate Garry et al.'s (1996) results, owing to these methodological differences. There were several procedural differences between the two studies (e.g., the use of 4 vs. 8 target events, the use of $15 \mathrm{vs} .32$ filler events, and the use of no cover story vs. a cover story at the beginning of the second administration of the LEI). Many of these methodological differences, in fact, reflect procedures introduced by Garry et al. (1997) in a study subsequent to their 1996 experiment. However, the important point in this study is that the findings of Garry et al. (1996) were replicated when the results were analyzed as in Garry et al. (1996); these data are presented in Figure 1. What is new here is the pattern of results for the events initially rated 5-8; these data are presented in Figure 2. Again, there is a similar pattern of results in both studies. Also, the similar pattern of results with the target events and the nontarget events in this study suggests that the findings in this study are not item-specific effects. Thus, the present results cannot be attributed to procedural differences between this study and that of Garry et al. (1996). Despite the procedural differences between the two studies, similar results were obtained when similar analyses were conducted.

It might also be argued that imagination inflation is supposed to occur for events that are originally rated as unlikely rather than likely to have occurred. According to this argument, imagining highly probable events could lead to planting new details in memory that conflict with details for related events already stored in memory. As a consequence, likelihood ratings would be reduced by imagining these highly probable events. This argument is not compelling, given that the increase in likelihood ratings from Time 1 to Time 2 for events initially rated low and the decrease in likelihood ratings from Time 1 to Time 2 for events initially rated high occurred for the imagined target events and the target events not imagined, as well as for the nontarget events. Thus, the results do not appear to be attributable to the cognitive process of imagining the target events.

It is evident from previous research that under some conditions, false events can be suggestively planted in memory (Hyman et al., 1995; Loftus \& Pickrell, 1995; Pezdek et al., 1997; Pezdek \& Roe, 1997). However, from the results of this experiment, along with those of Garry et al. (1996), it is clear that the act of thinking about or imagining a false event is not sufficient to plant that false event in memory. In the imagination inflation paradigm, the change in likelihood ratings from Time 1 to Time 2 for imagined events is accounted for by regression toward the mean, and not by a change in memory that results from imagining these events. Extensions of this research are needed to test whether there are any conditions under which imagination inflation for autobiographical memories does occur, above and beyond the effects of regression toward the mean.

In a recent study of individual differences in imagination inflation, using a procedure similar to that of Garry et al. (1996), Paddock et al. (1998) reported results similar to those of Garry et al. (1996). However, the results of Paddock et al. also focused on analyses of events initially rated $1-4$. They did include some analyses of all target events initially rated $1-7$, but they did not separately 
examine events with high versus low initial likelihood ratings. Because in most imagination inflation studies, only a minority of events receives initial high likelihood ratings ( $25 \%$ of the events in the present study), analyses that combine results for all events are not sensitive to the direction of the effect for events with initial high likelihood ratings. Furthermore, in Experiment 2, utilizing subjects who were not from a college population, Paddock et al. found no evidence of imagination inflation; imagining the target events did not inflate likelihood ratings from Time 1 to Time 2 .

In another study of imagination inflation, Mazzoni, Loftus, Seitz, and Lynn (1999) used a variation of the procedure of Garry et al. (1996). Likelihood ratings for events on the LEI were provided in the first LEI session and 3 or 4 weeks later in the second LEI session. One of the target events on the LEI was either "was harassed by a bully" or "was lost in a public place for more than one hour" before the age of two. One to 2 weeks after the first session, the subjects in the dream interpretation condition participated in what they were led to believe was an unrelated dream interpretation session. During the session, a "clinical psychologist" interpreted their dreams to suggest that a difficult childhood experience, such as being bullied/lost, appeared to have happened to them before the age of three. Control subjects did not have the dream interpretation session.

Mazzoni et al. (1999) reported that in the dream interpretation condition, likelihood ratings for the critical target item were more likely to increase than to decrease from Time 1 to Time 2. In the control condition, however, likelihood ratings for the target item were more likely to decrease than to increase from Time 1 to Time 2 . These results cannot be explained by regression toward the mean and suggest that imagination inflation did occur. There are two important procedural differences between the study by Mazzoni et al. and the present study. First, the dream interpretation session was temporally closer to the first than to the second administration of the LEI. As has been suggested by the results of Goff and Roediger (1998), this is an important factor in determining when imagination inflation occurs and when it does not. But second, the dream interpretation session was much more suggestive than simply having subjects imagine a target event. In the dream interpretation session, the subjects were provided with a reason why it was likely or plausible that they were bullied/lost as a child. Not surprisingly then, when they later rated how likely it was that they were bullied or lost as a child, their likelihood ratings increased. These results, however, do not appear to reflect a change in memory for the target event. When asked what they remembered about the target event from their childhood, only 2 of the 27 subjects in the dream condition reported additional details of the target event purported to have occurred before the age of three.

Psychologists are currently debating the extent to which false events can be suggestively planted in memory (see
Pezdek \& Banks, 1996, for a review). Although it is evident that some false events can be planted in memory under some conditions, it is not yet clear what the full range of these conditions is. From the results of this study, it is clear that one act of imagining a fictitious childhood event does not alone increase people's confidence that the event happened to them. When people simply think about or imagine a false event, this does not result in the false event's being implanted in memory. What may appear to be imagination inflation is actually a case of statistical regression toward the mean.

\section{REFERENCES}

Campbell, D. T., \& Kenny, D. A. (1999). A primer on regression artifacts. New York: Guilford.

Ceci, S. J., Huffman, M. L. C., Smith, E., \& Loftus, E. F. (1996). Repeatedly thinking about a non-event: Source misattribution among preschoolers. In K. P. Pezdek \& W. P. Banks (Eds.), The recovered memory/false memory debate (pp. 225-244). San Diego: Academic Press.

Cohen, G., \& Faulkner, D. (1989). Age differences in source forgetting: Effects on reality monitoring and on eyewitness testimony. Psychology \& Aging, 4, 10-17.

Garry, M., Manning, C. G., \& Loftus, E. F. (1997, July). A cognitive whodunit: Thinking about an event can make you think it happened to you. Paper presented at the meeting of the Society for Applied Research in Memory and Cognition, Toronto.

Garry, M., Manning, C. G., Loftus, E. F., \& Sherman, S. J. (1996) Imagination inflation: Imagining a childhood event inflates confidence that it occurred. Psychonomic Bulletin \& Review, 3, 208-214.

Garry, M., \& PolascheK, D. L. L. (2000). Imagination and memory. Current Directions in Psychological Science, 9, 6-10.

Goff, L. M., \& Roediger, H. L., III (1998). Imagination inflation for action events: Repeated imaginings lead to illusory recollections. Memory \& Cognition, 26, 20-33.

Hyman, I. E., Husband, T. H., \& Billings, F. J. (1995). False memories of childhood experiences. Applied Cognitive Psychology, 9, 181-197.

Loftus, E. F., \& Pickrell, J. E. (1995). The formation of false memories. Psychiatric Annals, 25, 720-725.

Mazzoni, G. A. L., Loftus, E. F., Seitz, A., \& Lynn, S. J. (1999). Changing beliefs and memories through dream interpretation. $A p$ plied Cognitive Psychology, 13, 125-144.

Paddock, J. R., Joseph, A. L., Chan, F. M., Terranova, S., ManNING, C. G., \& LofTus, E. F. (1998). When guided visualization procedures may backfire: Imagination inflation and predicting individual differences in suggestibility. Applied Cognitive Psychology, 12, 63-75.

Pezdek, K., \& BAnKs, W. P. (EDs.) (1996). The recovered memory/ false memory debate. San Diego: Academic Press.

Pezdek, K., Finger, K., \& Hodge, D. (1997). Planting false childhood memories: The role of event plausibility. Psychological Science, $\mathbf{8}$, 437-441.

Pezdek, K., \& Hinz, T. (in press). The construction of false events in memory. In H. Westcott, G. Davies, \& R. Bull (Eds.), Children's testimony: A handbook of psychological research and forensic practice. London: Wiley.

Pezdek, K., \& Hodge, D. (1999). Planting false childhood memories: The role of event plausibility. Child Development, 70, 887-895.

Pezdek, K., \& Roe, C. (1997). The suggestibility of children's memory for being touched: Planting, erasing and changing memories. Law \& Human Behavior, 21, 95-106.

\section{NOTE}

1. Contact Kathy Pezdek for specific directions on the step-by-step procedures for conducting this test of the significance of the mean residual difference. 


\section{APPENDIX \\ Modified Life Events Inventory (LEI) Used in This Study, With Target Events Starred}

1. Had a lifeguard pull you out of the water

2. Won a stuffed animal at a fair or carnival

3. Had your house robbed

4. Felt an earthquake

5. Adopted a lost animal

6. Cried when you had to go to the dentist

7. Gave someone a haircut

8. Shook hands with the Governor

9. Roasted marshmallows at a campfire

10. Found a $\$ 10$ bill in a parking lot*

11. Got sick while in school

12. Got mad at your family and ran away from home

13. Kissed your boyfriend or girlfriend at school

14. Saw a shooting star*

15. Were lost in a public place for more than an hour

16. Got sick and had to see the doctor late at night

17. Got stuck in a tree and had to have someone help you down*

18. Broke a window with your hand*

19. Got stung by a bee

(Manuscript received July 28, 1999;

revision accepted for publication September 27, 2000.) 